\title{
ANALISIS PENGARUH JUMLAH SUDU TERHADAP EFISIENSI TURBIN PELTON DENGAN TEKANAN KONSTAN
}

\author{
Niharman ${ }^{1}$, Antonius FA Silaen ${ }^{2}$, Een Tonadi 3 , Occa Coranda ${ }^{4}$ \\ Teknik Mesin, Fakultas Teknik, Universitas Prof. Dr. Hazairin, SH \\ E-mail: niharman.unihaz@gmail.com
}

\section{Informasi Naskah \\ Diterima: 16 April 2021 \\ Diterbitkan: 3 Juni 2021}

\begin{abstract}
One of the renewable energy sources that can be used for electricity generation is the pelton turbine. The purpose of this study was to determine the effect of the number of blades on the efficiency of a Pelton turbine with constant pressure. This research was conducted at the Unihaz mechanical engineering laboratory by varying the number of blades, namely 9 blade turbines and 12 blades. Tests were carried out by giving load gradually to the turbine until the turbine rotor rotation stopped rotating. The results show that in the turbine test with the blade 9 the maximum rotation achieved is $698.2 \mathrm{rpm}$ and the maximum rotor rotation is $714.5 \mathrm{rpm}$ at blade 12. Likewise, the torque coefficient and power coefficient achieved by the turbine with 12 are greater when compared to the 9 blades. Meanwhile, the efficiency that can be achieved by turbines with 9 blades is $71 \%$ and at 12 blades is $79 \%$. From this research it can be concluded that the number of blades affects the rotation, torque coefficient, power coefficient and efficiency of the Pelton turbine with constant pressure.
\end{abstract}

Keyword: Pelton Turbine, Blades, efficiency

\begin{abstract}
Abstrak: Salah satu sumber energi terbarukan yang dapat dimanfaatkan untuk pembangkit listrik adalah turbin pelton. Tujuan dari penelitian ini adalah untuk mengetahui pengaruh jumlah sudu terhadap efisiensi turbin pelton dengan tekanan konstan. Penelitian ini dilakukan di laboratorium teknik mesin Unihaz dengan memvariasikan jumlah sudu yaitu turbin sudu 9 dan sudu 12. Pengujian dilakukan dengan memberikan beban secara bertahap ke turbin sampai putaran rotor turbin berhenti berputar. Hasilnya menunjukkan pada pengujian turbin dengan sudu 9 putaran maksimal yang dicapai adalah 698,2 rpm dan pada sudu 12 didapat putaran rotor maksimal 714,5 rpm. Begitu juga dengan koefisien torsi dan koefisien daya yang dicapai turbin dengan 12 lebih besar jika dibandingkan dengan sudu 9. Sementara efisiensi yang dapat dicapai turbin dengan sudu 9 adalah sebesar $71 \%$ dan pada sudu 12 sebesar $79 \%$. Dari penelitian ini dapat disimpulkan bahwa jumlah sudu berpengaruh terhadap putaran, koefisien torsi, koefisien daya dan efisiensi turbin pelton dengan tekanan konstan.
\end{abstract}

Kata Kunci: Turbin Pelton, Sudu, Efisiensi

\section{PENDAHULUAN}

Salah satu sumber energi terbarukan yang dapat dimanfaatkan untuk pembangkit listrik adalah energi air. Pemanfaatan energi air tersebut adalah dengan memanfaatkan energi potensial yang tersedia yang meliputi potensi tinggi air terjun dan kecepatan. Untuk memanfaatkan energi potensial tersebut adalah dengan menggunakan turbin air (Yani dkk, 2018)-(Frisca dkk, 2018). Turbin air ialah suatu mesin fluida yang mampu merubah energi potensial air menjadi energi mekanik dan oleh sebuah generator energi mekanik tersebut diubah menjadi energi listrik (Irawan, D, 2018).

Turbin air dibedakan kedalam dua golongan utama yaitu turbin impuls dan 
turbin reaksi. Turbin pelton adalah jenis turbin impuls yang memanfaatkan jatuh air (head) yang tinggi walaupun dengan debit air yang kecil. Turbin jenis ini menggunakan nozel dalam bentuk pancaran air dan diterima oleh sudu-sudu turbin sehingga menghasilkan putaran yang diteruskan ke poros generator untuk menghasilkan energi listrik.

Turbin pelton mampu menghasilkan daya yang besar, konstruksinya sederhana., perawatannya mudah dan teknologi yang digunakan sederhana sehingga mudah untuk diterapkan di daerahdaerah terpencil.

Beberapa penelitian terlebih dahulu menyebutkan bahwa jumlah sudu pada turbin pelton berpengaruh terhadap kinerja turbin pelton. Pada penelitian ini bertujuan untuk mengetahui pengaruh jumlah sudu turbin terhadap efisiensi turbin pelton dengan tekanan konstan.

\section{TINJAUAN PUSTAKA}

\section{1). Turbin Air}

Turbin air adalah turbin yang dengan media kerjanya berupa air. Turbin umumnya terdiri dari poros dan sudusudu. Sudu turbin biasanya terdiri dari sudu tetap (stationary blade) dan sudu putar (rotary blade). Sudu tetap berfungsi mengarahkan aliran fluida dan tidak ikut berputar. Sementara sudu yang berfungsi mengubah arah dan kecepatan aliran fluida sehingga timbul gaya putar pada poros disebut sudu putar. Selanjutnya putaran poros tersebut dimanfaatkan untuk menggerakkan generator sehingga menghasilkan energi listrik (Jasa, L, 2015). Turbin air dapat dikelompokkan menjadi dua yaitu:

1. Turbin Reaksi merupakan turbin air yang mampu merubah seluruh energi air yang tersedia menjadi energi mekanik (putar). Runner dari turbin ini sepenuhnya berada di dalam air dengan sebuah rumah turbin yang melingkupinya. Turbin reaksi dapat digunakan pada head rendah hingga sedang. Turbin perancis dan turbin kaplan merupakan contoh turbin reaksi.
2. Turbin Impuls merupakan turbin air yang mampu merubah seluruh energi air (energi potensial, tekanan dan kecepatan) yang tersedia menjadi energi kinetik. Pada nozel energi potensial air diubah menjadi energi kinetik. Air dengan kecepatan tinggi yang keluar dari nozel membentur sudu-sudu turbin yang mengakibatkan arah kecepatan aliran berubah. Hal itu menyebabkan terjadinya perubahan momentum (impuls) dan roda turbin akan berputar. Turbin yang termasuk ke dalam jenis turbin impuls adalah turbin pelton, turbin turgo dan turbin cross flow.

\section{2). Turbin Pelton}

Turbin pelton merupakan salah satu jenis turbin impuls yang bekerja pada head yang besar. Turbin pelton memiliki satu set runner dengan sudu-sudu yang dipasang secara berjajar pada sebuah disk seperti ditunjukkan pada gambar 1. Prinsip kerja dari turbin pelton ini adalah merubah gaya potensial air menjadi gaya mekanis. Selama pancaran air yang keluar melalui nozel dengan kecepatan tinggi menyemprotkan sudu maka runner dapat berputar. Perputaran ini selanjutnya melalui sebuah pulley dan belt diteruskan ke generator sehingga generator berputar dan menghasilkan listrik. Turbin pelton memiliki berbagai kelebihan jika dibandingkan dengan turbin lainnya yaitu: a). Konstruksinya sederhana; b). Baik dikembangkan pada kondisi air dengan debit kecil tapi memiliki head tinggi; c). Daya yang dihasilkan besar; d). Perawatan dan pemeliharaannya relatif mudah dan teknologi yang digunakan sederhana (Saleh, M. 2018).
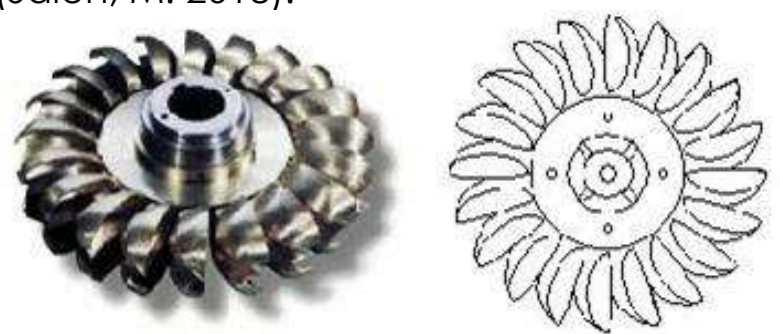

Gambar 1. Runner Turbin Pelton (http://eprints.polsri.ac.id/5465/3/FILE\%20II\%20BAB\%20II.pd f) 
Beberapa penelitian terdahulu telah menyimpulkan bahwa jumlah sudu berpengaruh terhadap kinerja turbin pelton. Mafruddin akk telah menguji pengaruh jumlah sudu dan diameter nozel terhadap kinerja turbin pelton. Hasilnya mereka menyimpulkan bahwa jumlah sudu dan diameter nozel berpengaruh terhadap daya turbin. Daya turbin maksimal diperoleh pada jumlah sudu 21 dengan diameter nozel $8 \mathrm{~mm}$ yaitu sebesar 2,15 watt (Mafruddin dkk, 2019). Sementara itu Donny dkk, melakukan studi analisis pengaruh model sudu turbin terhadap putaran pada turbin pembangkit listrik tenaga mikro hidro (PLTMH). Mereka menguji model sudu turbin setengah lingkaran, segitiga dan model sirip. Hasilnya disimpulkan bahwa turbin berbentuk segitiga adalah yang paling baik (Donny C. 2017).

Kemudian I Gusti dkk telah melaksanakan penelitian tentang pengaruh jumlah sudu pada prototype PLTMH dengan menggunakan turbin pelton terhadap efisiensi yang dihasilkan. Hasilnya menunjukkan bahwa jumlah sudu terbaik adalah 22.

\section{3). Perhitungan Turbin Pelton}

a. Diameter pada tali (belt) Gaya yang menimbulkan torsi pada Pulley $\Delta F=(F$ pegas + F beban) $\times g$ (Newton) ..... (1)

Dimana :

$g$ = gravitasi

b. Torsi (T)

$$
\mathrm{T}=\Delta F \times\left(\frac{\mathrm{D} \text { pulley }+\mathrm{D} \text { tali }}{2}\right)
$$

c. Kesepatan sudu pada putaran $(\omega)$

$(\omega)=\frac{2 \pi n}{60}(\mathrm{rad} / \mathrm{s})$

d. Kecepatan tangesial sudu

$\checkmark$ rotor $=\frac{\pi d n}{60}(\mathrm{~m} / \mathrm{s})$

e. Tip Speed Ratio $(\lambda)$
$\lambda(\mathrm{TSR})=\frac{V \text { rotor }}{V \text { air }} \ldots . . .(5)$

f. Daya Turbin (Pturbin)

Pturbin $=\mathrm{T} . \omega$ (watt)

Dimana:

$\mathrm{T}=$ Torsi $(\mathrm{Nm})$

$\omega=$ Kecepatan sudu rotor ( $\mathrm{rab} / \mathrm{s}$ )

g. Daya Air (P air)

$\mathrm{P}$ air $=1 / 2 \cdot \rho \cdot \mathrm{A} \cdot V^{3}$ air (watt)

Dimana:

$\rho=$ Berat jenis air $\mathrm{kg} / \mathrm{m}^{3}$

$A=$ Luas bidang turbin $m^{2}$
$\mathrm{V}=$ Kecepatan air $\mathrm{m} / \mathrm{s}$

h. Koefisien daya (Cp)

$\mathrm{Cp}=\frac{P \text { turbin }}{P \text { air }}$

i. Efisiensi ( $\eta$ )

$$
\eta=C p \times 100 \%
$$

j. Koefisien torsi ( $\mathrm{CT}$ )

$$
\mathrm{C} t=\frac{T}{\frac{1}{2} X \rho X V^{3 X A X r}}=\frac{C p}{\lambda} \ldots . . \text { (9) }
$$

\section{METODOLOGI PENELITIAN}

Tahapan pelaksanaan penelitian ini sebagaimana ditunjukkan pada gambar 2 dimulai dari studi literatur, perumusan masalah dan tujuan penelitian. Selanjutnya adalah perancangan turbin pelton, pembuatan dan perakitan turbin pelton. Pada proses pembuatan dan perakitan turbin dimulai dari persiapan alat dan bahan, proses pengukuran, pemotongan, penyambungan serta perakitan. Tahapan selanjutnya adalah uji coba alat. Apabila hasil uji coba turbin sudah bekerja dengan baik maka selanjutnya adalah proses pengujian dan pengambilan data dengan variasi jumlah sudu. Hasil pengambilan data kemudian dianalisis dan dihitung menggunakan rumus-rumus kemudian disajikan dalam bentuk diagram-diagram. 


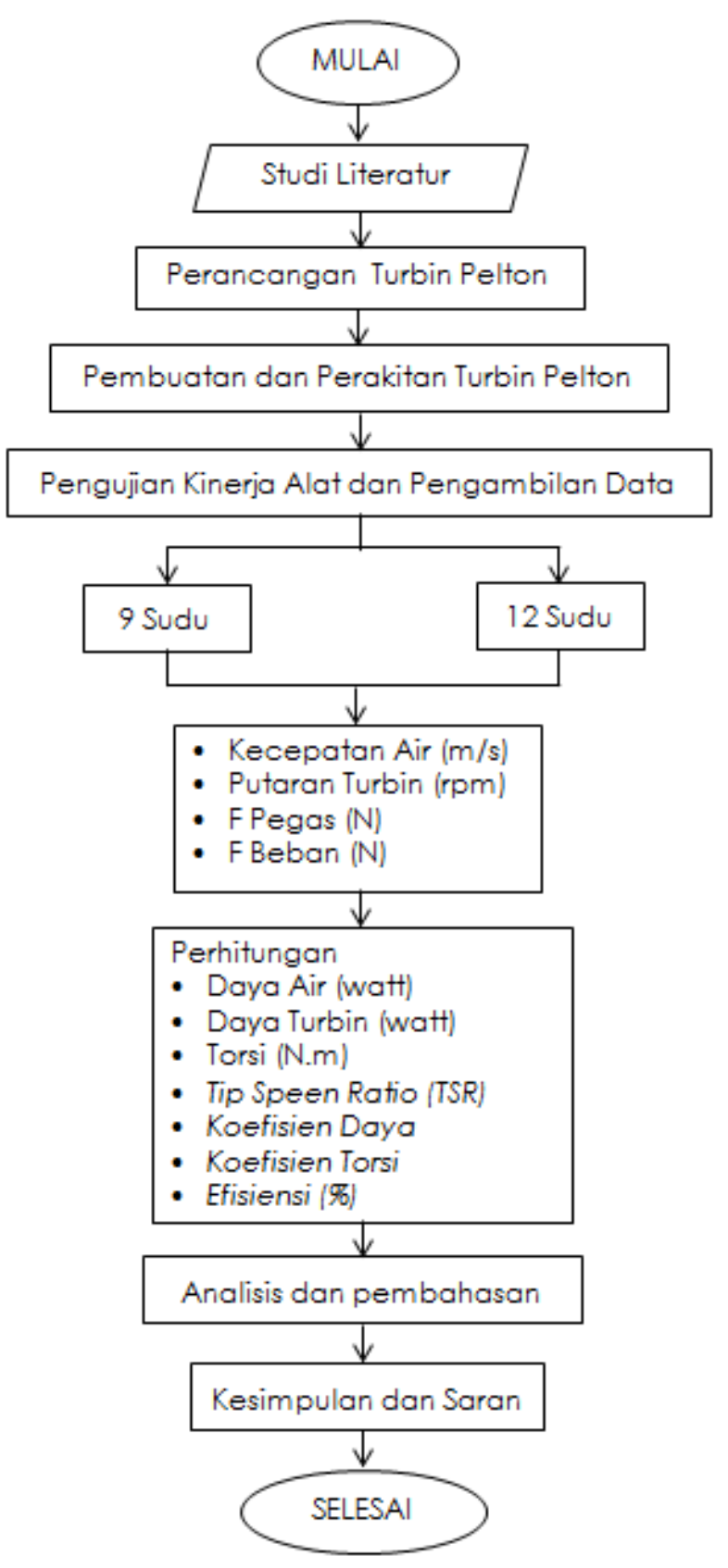

Gambar 2. Tahapan Penelitian

Bahan yang digunakan dalam pembuatan instalasi turbin pelton ini antara lain adalah: Pipa L bow 5/8 inci sebagai bahan sudu, akrlilik, poros, baut dan mur, bantalan, pipa PVC, pulley, pompa, bak penampungan, besi siku untuk rangka dan lain-lain. Peralatan yang digunakan meliputi perlengkapan las listrik, gerinda, bor, meteran, toolset, peralatan keselamatan kerja dan lain-lain. Alat untuk pengujian dan pengambilan data pada penelitian ini antara lain adalah tachometer untuk mengukur putaran turbin, neraca pegas untuk mengukur gaya beban turbin.

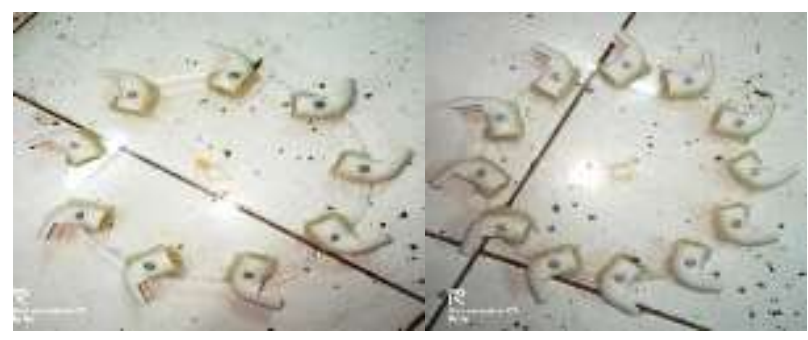

Gambar 3. Sudu 9 dan sudu 12

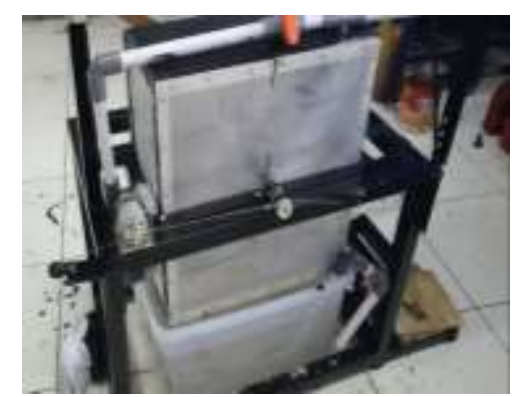

Gambar 4. Instalasi turbin pelton

\section{HASIL PENELITIAN DAN PEMBAHASAN}

Setelah dilakukan pengujian dan perhitungan maka didapat bahwa pengujian turbin dengan 9 sudu.

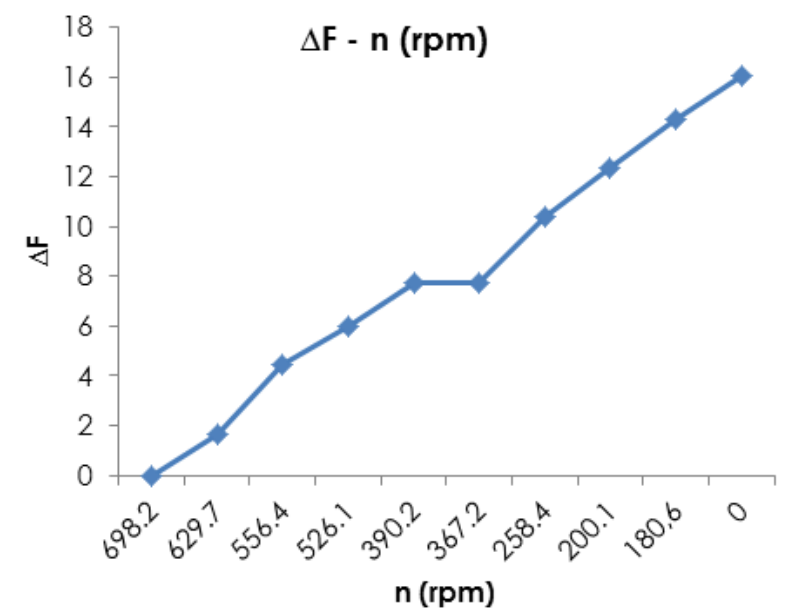

Gambar 5. $\Delta F$ vs $n$ (rpm) pada sudu 9

Grafik pada gambar 5 menunjukkan bahwa pada $\Delta F 0$ didapat putaran turbin sebesar 698,2 rpm. Semakin besar gaya yang bekerja maka kecepatan rotor semakin menurun sampai pada nilai $\Delta F$ maksimum 16,04 maka rotor berhenti berputar.

Selanjutnya pada gambar 6 merupakan grafik koefisien torsi dengan Tip Speed Rapid (TSR). Hasilnya menunjukkan pada sudu 9 didapat CT max 0,95 pada $\lambda$ 0,65 dengan rentang batasan torsi pada 0,65 $<\lambda<2,68$. 


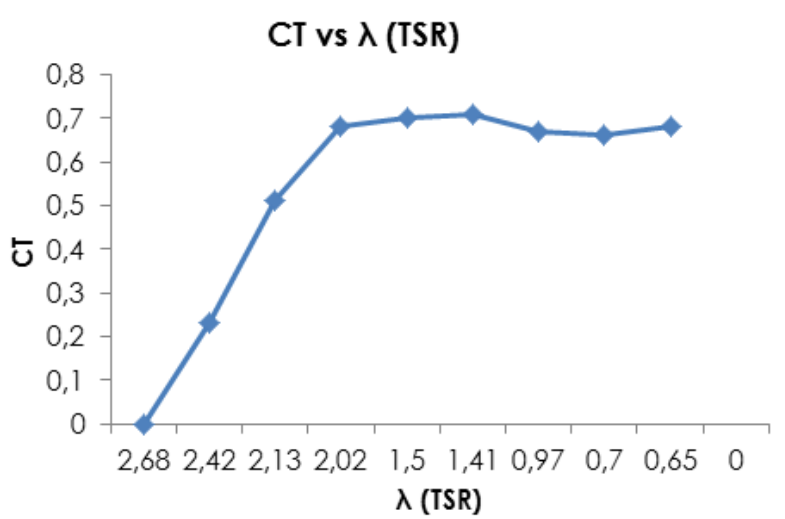

Gambar 6. Hubungan Koefisien Torsi (CT) dengan TSR

Kemudian pada gambar 7 di bawah diperlihatkan grafik koefisien daya (Cp) terhadap $\lambda$ (TSR) turbin pelton dengan jumlah sudu 9. Hasilnya didapat nilai $\mathrm{Cp}$ maksimal yaitu sebesar 0,71 pada $\lambda 1,41$ dengan efisiensi maksimum 71\%. Grafik koefisien daya $\mathrm{Cp}$ dan $\lambda$ menunjukkan profil menurun sampai pada posisi nol yang berarti rotor turbin berhenti karena besarnya gaya yang bekerja pada poros.

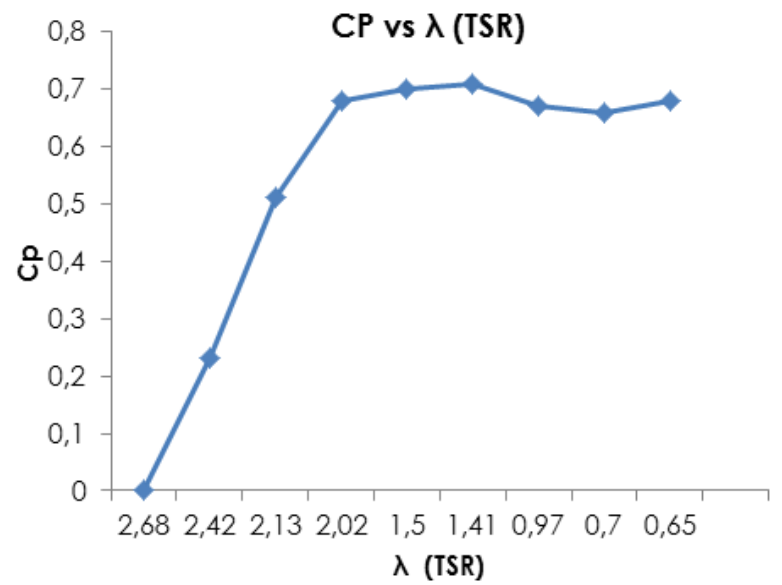

Gambar 7. Koefisien Daya (CT) dengan TSR

Selanjutnya hasil pengujian turbin pada sudu 12 sebagaimana ditampilkan pada gambar 8 menunjukkan profil grafik perbandingan antara delta $F$ dengan kecepatan putar rotor turbin. Profil grafik tersebut sejalan dengan hasil pengujian pada sudu 9. Semakin besar gaya yang diberikan maka semakin menurun putaran turbin sampai akhinya turbin berhenti berputar. Namun pada turbin sudu 12 nilai $\Delta \mathrm{F}$ maksimal yang dapat dicapai adalah sebesar 26,72. Sementara putaran maksimum yang dicapai rotor $714,5 \mathrm{rpm}$.

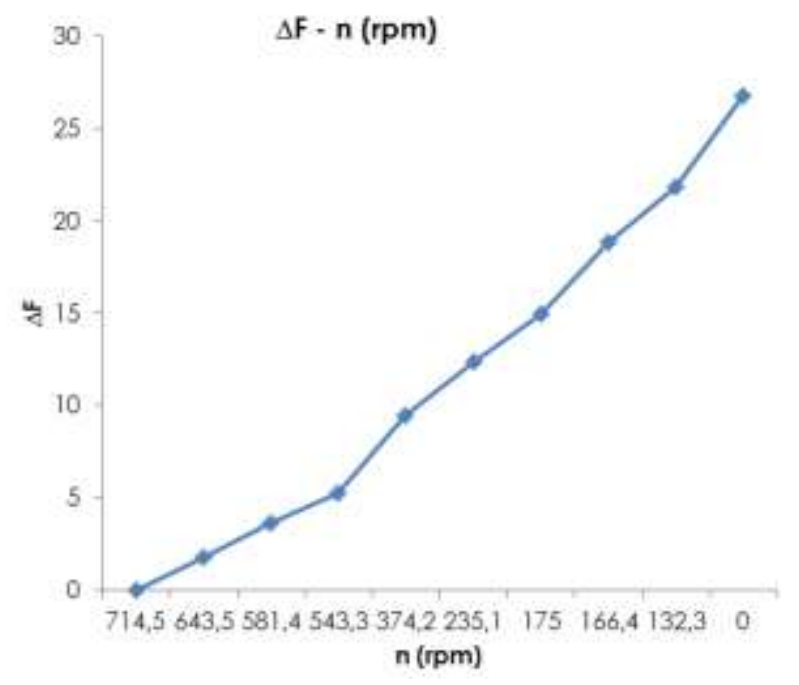

Gambar 8 Delta F dengan putaran turbin pada turbin 12 sudu

Pada gambar 9 menunjukkan grafik koefisien torsi dengan Tip Speed Ratio (TSR) pengujian turbin pelton dengan jumlah sudu 12. Hasilny menunjukkan CT maksimal adalah 1,38 pada TSR 0,50 dengan batasan torsi pada $0,50<\lambda<$ 2,74 .

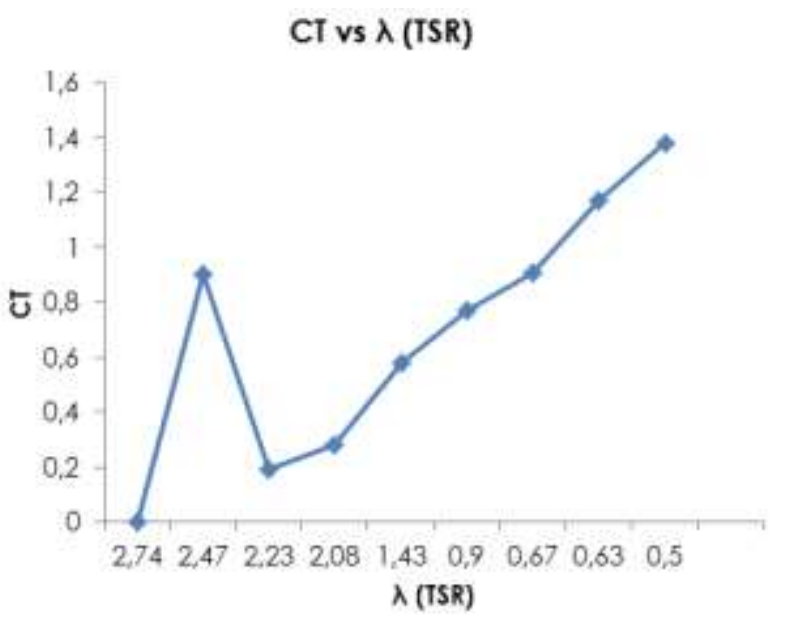

Gambar 9. Perbandingan Koefisien Torsi dengn TSR Sudu 12

Kemudian pada gambar 10 menampilkan grafik hubungan koefisien daya dengan TSR pada turbin sudu 12 . Hasilnya memperlihatkan profil yang berbanding IUrus antara koefisien daya dengan TSR. Hasilnya didapat nilai koefisien daya maksimal itu sebesar 0,79 pada TSR 1,43, sehingga diperoleh efisiensi maksimal yaitu sebesar $79 \%$. 


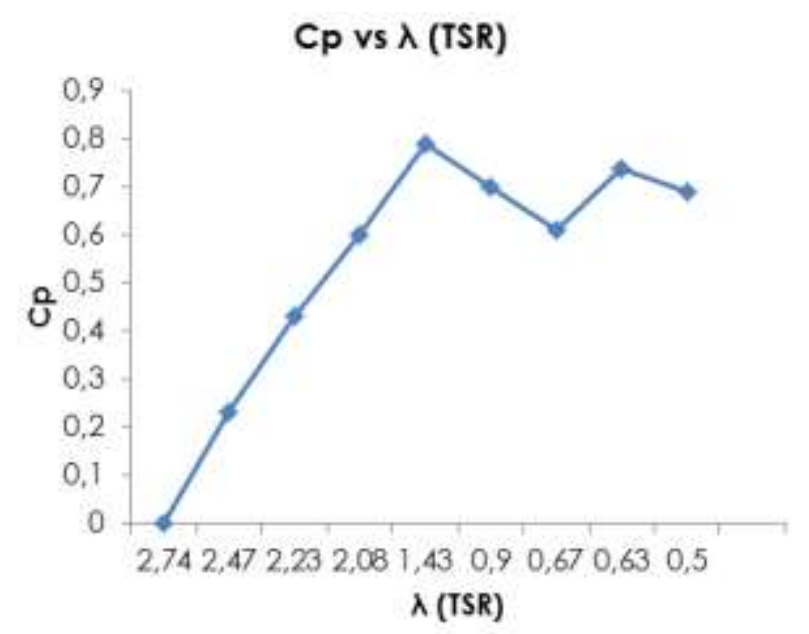

Gambar 10. Perbandingan Koefisien Torsi dengan TSR sudu 12

Gambar 11 menunjukkan perbandingan koefisien torsi antara turbin sudu 9 dengan turbin sudu 12. Hasilnya menunjukkan nilai koefisien torsi pada sudu 12 lebih besar jika dibandingkan dengan koefisien torsi turbin dengan sudu 9.

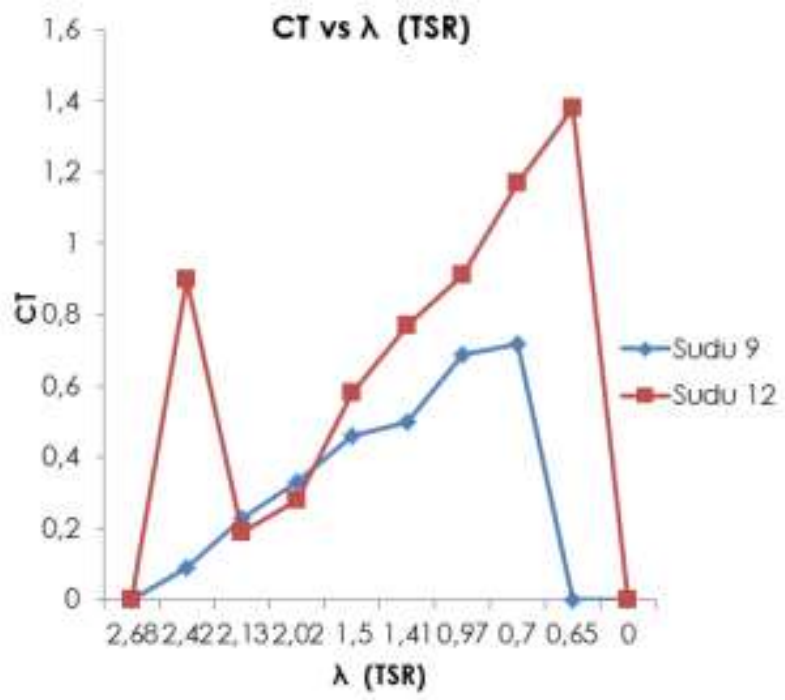

Gambar 11. Perbandingan Koefisien Torsi antara turbin sudu 9 dengan sudu 12.

Selanjutnya perbandingan koefisien daya (CP) turbin sudu 9 dengan sudu 12. Pada gambar 12 menunjukkan profil koefisien daya yang dihasilkan sudu 12 lebih besar jika dibandingkan dengan sudu 9.

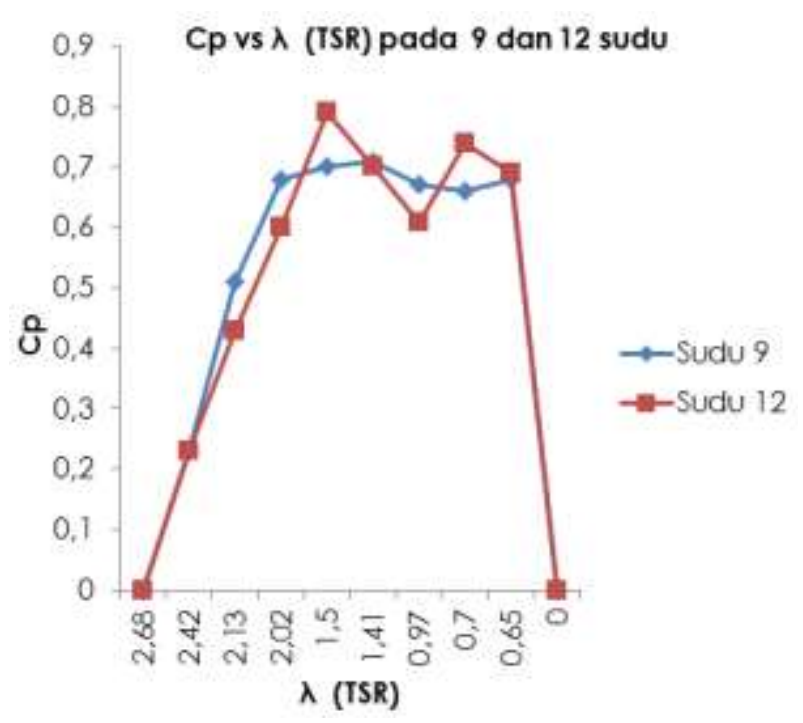

Gambar 12. Perbandingan Koefisien Daya antara turbin sudu 9 dengan sudu 12

\section{KESIMPULAN}

Dari hasil peneilitian di atas maka dapat disimpulkan bahwa pada tekanan konstan, jumlah sudu berpengaruh terhadap kinerja turbin pelton. Dalam hal ini putaran dan beban yang dapat dicapai turbin dengan sudu 12 lebih besar jika dibandingkan turbin dengan sudu 9 . Begitu juga dengan efisiensi yang dapat dicapai oleh turbin pelton dengn sudu 12 lebih besar jika dibandingkan dengan turbin sudu 9 yaitu masing-masing $79 \%$ untuk sudu 12 dan $71 \%$ pada sudu 9 .

\section{UCAPAN TERIMA KASIH}

Terima kasih penulis sampaikan kepada tim Labaoratorium Teknik Mesin Unihaz atas segala dukungan dan bantuannya terutama dalam penggunaan lab untuk penelitian ini.

\section{DAFTAR PUSTAKA}

Ahmad Yani, Budi Susanto, Rosmiati. (2018). Analisis Jumlah Sudu Mangkuk Terhadap Kinerja Turbin Pelton Pada Alat Praktikum Turbin Air. Jurnal Teknik Mesin Univ. Muhammadiyah Metro, 7(2), 185-192.

Donny Christiawan, 2017. Studi analisis pengaruh model sudu terhadap putaran pembangkit listrik tenaga mikro hidro (PTLMH). Jurnal Teknologi Elektro, 16(2), $104-111$.

Frisca Anugra Putra. (2018). Analisa Pengaruh Sudut Sudu dan Debit 
Aliran Terhadap Performa Turbin Kaplan. Universitas 17 Agustus 1945 Surabaya. Skripsi.

Irawan, D. (2018). Prototype Turbin Pelton Sebagai Energi Alternatif Mikrohidro di Lampung. Metro, Lampung: Universitas Muhammadiyah.

I Gusti dkk. (2017). Pengaruh jumlah sudu pada prototype PLTMH dengan menggunakan turbin pelton terhadap efisiensi yang dihasilkan. Jurnal Spektrum, 7(4), 162-172.

Jasa, L. (2015). Peningkatan Efisiensi Turbin dengan Pembaruan Desain Turbin Banki untuk Mikro Hidro di Daerah Tropis. Surabaya: Institut Teknologi Sepuluh Nopember.

Mafruddin dkk. (2019) Pengaruh Jumlah Sudu dan Diameter Nozel terhadap Kinerja Tuurbin Pelton. Turbo:Jurnal Program Studi Teknik Mesin UM Metro, 8(2), 214-218.

Saleh, M. (2018). Perancangan Alat Uji Prestasi Turbin Pelton. Pengaraian, Riau : Universitas Pasir Pengaraian. 